\title{
Duodenal histology, ulceration, and Helicobacter pylori in the presence or absence of non-steroidal anti-inflammatory drugs
}

\author{
A S Taha, S Dahill, I Nakshabendi, F D Lee, R D Sturrock, R I Russell
}

\begin{abstract}
Duodenitis and gastric metaplasia, which is often colonised by Helicobacter pylori (H pylori), are increasingly recognised for their importance in the pathogenesis of duodenal ulcers. The situation is not clear in patients receiving non-steroidal anti-inflammatory drugs (NSAIDs), who have a higher risk of peptic ulceration. The aim of this study was to identify the duodenal histological abnormalities in the presence or absence of NSAIDs, $H$ pylori, and duodenal ulceration. Endoscopic duodenal biopsy specimens were taken from healthy looking mucosa of 172 patients (74 took NSAIDs, and 98 did not). Duodenitis was graded according to the degree of neutrophilic and plasma cell infiltration, villus height, Brunner's gland prolapse, and gastric metaplasia. The activity of duodenitis was dependent on the neutrophilic infiltration. A global score covering all the above factors was constructed, and $\boldsymbol{H}$ pylori in both the stomach and duodenum, was also assessed. The results showed that duodenitis with varying degrees of neutrophilic infiltration and gastric metaplasia was found in 20 patients (27\%) taking NSAIDs, compared with 56 patients $(57 \%)$ not taking NSAIDs $\left(\chi^{2}=16.24, p<0.001\right)$. This degree of duodenitis was also found in 20 of 25 patients $(80 \%)$ with duodenal ulcers, regardless of NSAID intake $\left(\chi^{2}=15.38, p<0.001\right)$. Gastric metaplasia was identified in 20 patients $(27 \%)$ receiving NSAIDs and $38(39 \%)$ not receiving NSAIDs. Duodenal $H$ pylori was only seen in patients with gastric metaplasia $10(50 \%)$ receiving NSAIDs, and $34(89 \%)$ not receiving NSAIDs. $H$ pylori positive gastritis, and the combination of active duodenitis and gastric metaplasia were independent predictors of duodenal ulceration. It is concluded that active duodenitis is less common in patients taking NSAIDs, but is strongly associated with gastric metaplasia, $\boldsymbol{H}$ pylori positive gastritis, and duodenal ulceration. These findings are relevant to the pathogenesis and treatment of duodenal ulcers in patients taking NSAIDs.

(Gut 1993; 34: 1162-1166)
\end{abstract}

Gastritis and duodenitis have, for a long time, been thought to play a part in the pathogenesis of peptic ulcer disease, and this concept has been further consolidated by the recognition of Helicobacter pylori (H pylori). ${ }^{2}$ Subsequently, it has been suggested that gastric metaplasia in the duodenum and $H$ pylori associated gastritis might be synergistic in the pathogenesis of duodenitis, with the metaplastic gastric epithe- lium allowing $H$ pylori to colonise the duodenal mucosa, where it produces an acute inflammatory response. ${ }^{3}$ Most studies in this field have been carried out in patients not taking nonsteroidal anti-inflammatory drugs (NSAIDs), and the role of duodenitis and gastric metaplasia in mediating NSAID related damage has, therefore, remained unclear.

We aimed at studying the histology of the duodenal mucosa in the presence or absence of chronic NSAID intake, $H$ pylori, and duodenal ulcers.

\section{Patients and methods}

Patients, aged 18 years or over, were recruited from the Rheumatology and the Gastroenterology outpatient clinics, provided they had no malignancy or previous history of gastric or duodenal surgery. NSAIDs had to be taken for a minimum of four weeks before endoscopy. Patients were excluded if they had taken ulcer healing agents, antibiotics, or cytotoxic drugs within one week of endoscopy. Informed consent was obtained, and endoscopy performed using 3-7 mg midazolam intravenously for sedation.

At endoscopy, an average of two biopsy specimens were taken from the anterior and posterior walls of the first part of the duodenum, and immediately fixed in a solution of $10 \%$ formalin $/$ saline. The duodenal histological findings were reported as follows:

Normal - with villus to crypt ratio greater than $2: 1$, in the presence or absence of Brunner's glands above the muscularis mucosa, but without any increase in the numbers of inflammatory cells.

Chronic duodenitis - in the presence of mucosal mononuclear cell infiltration and epithelial damage.

Active chronic duodenitis - this was diagnosed whenever intramucosal neutrophils were seen, in the presence or absence of gastric metaplasia, and especially in the background of mononuclear cell infiltration.

The severity of the above findings (duodenitis, villus height, and Brunner's gland prolapse) was graded on a $0-3$ scale: 0 , normal; 1 , mild; 2 , moderate; and 3, severe.

The extent of gastric metaplasia was assessed as follows: 0 , absent; 1 , present but consisting of less than five consecutive cells; 2 , five consecutive cells; and 3 , greater than five consecutive cells, seen in 1-3 sections cut at three levels in each biopsy specimen.

A global score covering the overall totals of the scores of all the above assessments was con- 
TABLE I Demographic and endoscopic details of the study groups

\begin{tabular}{lll}
\hline & $\begin{array}{ll}\text { Receiving } \\
\text { NSAID }\end{array}$ & $\begin{array}{l}\text { Not receiving } \\
\text { NSAID }\end{array}$ \\
\hline No & 74 & 98 \\
Men & 24 & 38 \\
Women & 50 & 60 \\
Age (y), median (interquartile & $57(48-65)$ & $52(40-61)$ \\
range) & & \\
Smokers & 27 & 56 \\
Drinkers & 28 & 44 \\
Abdominal symptoms & 43 & 83 \\
Gastric ulcers & 17 & 2 \\
Duodenal ulcers & 11 & 14 \\
Gastric erosions & 7 & - \\
\hline
\end{tabular}

structed: in the absence of neutrophils, patients scoring four or less were considered normal; those scoring five or more were considered to have chronic duodenitis, in the absence of neutrophils. Chronic active duodenitis was diagnosed when intramucosal neutrophils were seen in patients scoring four or more.

The presence or absence of $H$ pylori in the duodenal mucosa was also assessed using cresyl violet stain, and by culture of single duodenal biopsy specimens. Detection of $H$ pylori by either histology or culture was considered as indicative of active infection in the duodenum.

Gastric antral biopsy specimens were also taken to check for the presence of $H$ pylori by histology (2 specimens) and culture (1 specimen), as previously described. ${ }^{4}$

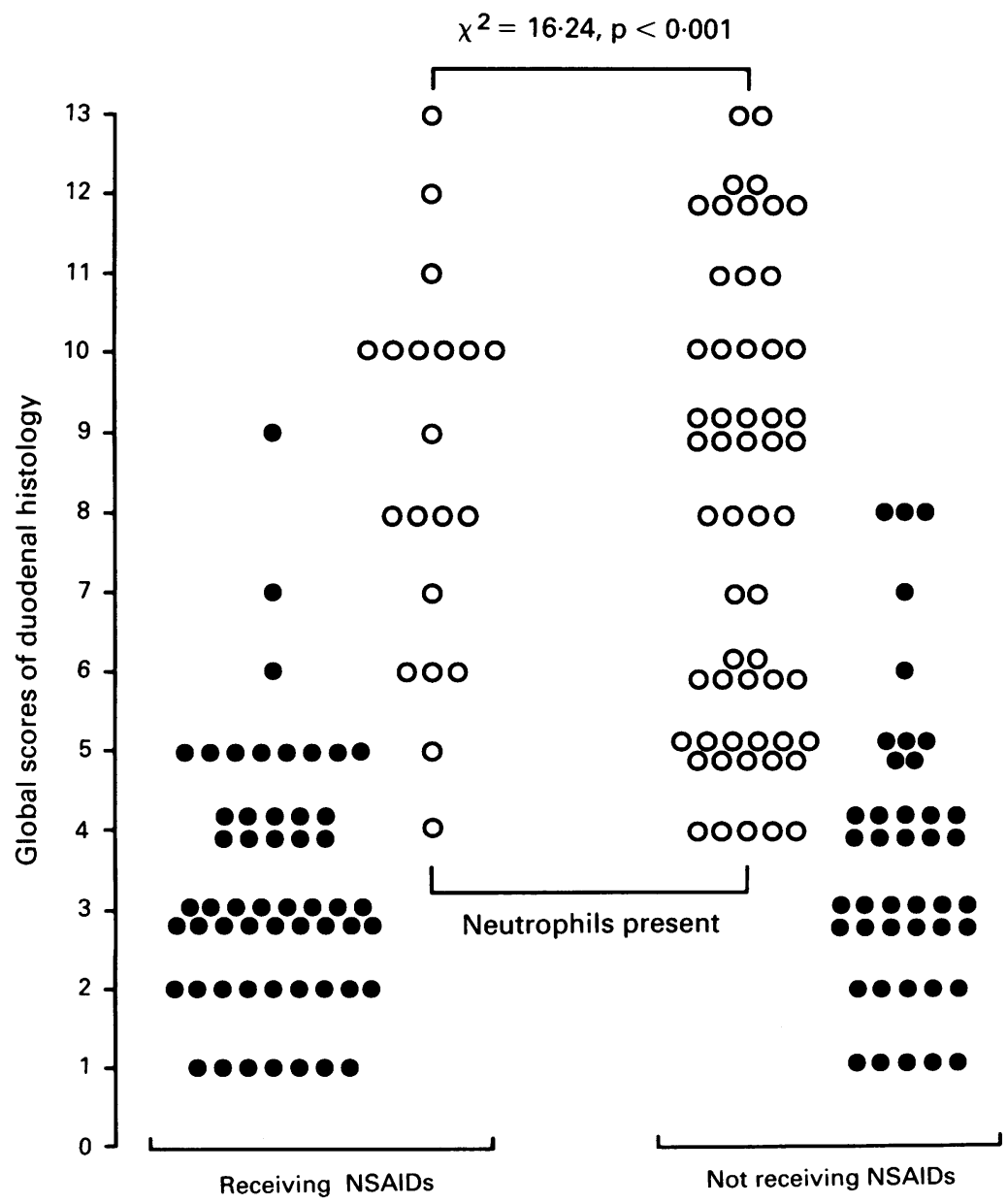

The duodenal global histological scores in the presence or absence of NSAIDs. Patients with intramucosal neutrophils have active chronic duodenitis. The remainder (black dots) have inactive chronic inflammation, and their numbers were similar in the two study groups.
Gastritis was classified according to the Sydney System, which also covers chemical and lymphocytic gastritis. ${ }^{5-8}$

Statistical analyses included the $\chi^{2}$ test, analysis of variance, multiple and logistic regression where appropriate. All specimens carried code numbers, and the endoscopist and pathologists were not aware of any treatment being received by patients. The histological scoring was performed by the two pathologists separately in order to assess reproducibility.

\section{Results}

A total of 172 patients were studied: 74 were receiving NSAIDs, and 98 were not. Table I shows the demographic data of the patients. Patients of both groups were comparable in their ages and in their smoking and drinking habits. Patients treated with NSAIDs had more gastric but a similar number of duodenal ulcers as those not taking NSAIDs. None of the study subjects received any drug prohibited by the study protocol within six months of endoscopy, apart from four patients (not on NSAIDs), who took antibiotics for chest infection, two to three months before recruitment. Also, abdominal complaints in most of the symptomatic patients not taking NSAIDs have settled once their endoscopy was reported normal: irritable bowel (or stomach) syndrome, or non-ulcer dyspepsia cannot be excluded in these patients.

The Figure shows the duodenal global histological scores. The histological scores of one pathologist were reproduced by his other fellow pathologist in more than $90 \%$ of specimens, regardless of NSAID intake. Patients in the NSAID group had fewer cases of active chronic duodenitis. There was no significant difference in the number of patients with chronic duodenitis ( 11 receiving NSAIDs and 10 not receiving NSAIDs).

Table II describes the patients with active chronic duodenitis. The two groups were similar with respect to the number of smokers, patients with gastric $H$ pylori, gastric metaplasia, and duodenal ulcers. Grade 3 (heavy) neutrophilic and plasma cell infiltration, however, was more prevalent in the absence of NSAIDs. It is also worth noting that patients with active chronic duodenitis in both groups had a total of 20 of 25 duodenal ulcers $(80 \%)$ diagnosed in all patients $\left(\chi^{2}=15 \cdot 38, \mathrm{p}<0.001 v\right.$ patients without active duodenitis). Duodenal $H$ pylori was found in only $50 \%$ of patients taking NSAIDs with active duodenitis, and $61 \%$ of their counterparts not

TABLE II Characteristics of patients with active chronic duodenitis

\begin{tabular}{lll}
\hline & $\begin{array}{l}\text { Receiving } \\
\text { NSAID } \\
(n=74)(\%)\end{array}$ & $\begin{array}{l}\text { Not receiving } \\
\text { NSAID } \\
(n=98)(\%)\end{array}$ \\
\hline No & $20(27)$ & $56(57)^{\star}$ \\
Smokers & $12(60)$ & $37(66)$ \\
Gastric $H$ pylori & $20(100)$ & $43(77)$ \\
Duodenal $H$ pylori & $20(100)$ & $43(77)$ \\
Gastric metaplasia & $14(70)$ & $34(61)$ \\
Heavy neutrophilic infiltration & $4(20)$ & $17(30)^{\star \star}$ \\
Heavy mononuclear infiltration & $2(10)$ & $12(21)^{\star \star}$ \\
Duodenal ulcers & $6(30)$ & $14(25)$ \\
\hline
\end{tabular}

Significant rise: ${ }^{\star} \mathrm{p}=<0 \cdot 001 ;{ }^{\star \star} \mathrm{p}=<0 \cdot 05$ 
TABLE III Details of patients with gastric metaplasia in the duodenum

\begin{tabular}{lll}
\hline & $\begin{array}{l}\text { Receiving } \\
\text { NSAID } \\
(n=74)(\%)\end{array}$ & $\begin{array}{l}\text { Not receiving } \\
\text { NSAID } \\
(n=98)(\%)\end{array}$ \\
\hline No & $20(27)$ & $38(39)$ \\
Grade: 1 & $4(20)$ & $6(16)$ \\
3 & $16(80)$ & $32(84)$ \\
Smokers & $12(60)$ & $24(62)$ \\
Gastric $H$ pylori & $14(70)$ & $34(89)$ \\
Duodenal $H$ pylori & $10(50)$ & $34(89)$ \\
Active chronic duodenitis & $14(70)$ & $34(89)$ \\
Heavy neutrophilic infiltration & $4(20)$ & $15(39)$ \\
Heavy mononuclear infiltration & $1(5)$ & $8(24)$ \\
Duodenal ulcers & $6(30)$ & $10(26)$ \\
\hline
\end{tabular}

taking NSAIDs; all cases of duodenal $H$ pylori coexisted with gastric metaplasia.

Table III shows the characteristics of patients with gastric metaplasia; although there were relatively fewer cases of metaplasia in patients taking NSAIDs, the differences were not statistically significant. Also, patients not treated with NSAIDs were more likely to have heavy neutrophilic and mononuclear cell infiltration. The two groups were almost identical, however, in the extent of metaplasia, the number of smokers, patients with gastric $H$ pylori, and duodenal ulcers. Similar to patients with active chronic duodenitis, most of the patients with duodenal ulcers $(16 / 25,64 \%)$ were also found to have gastric metaplasia $\left(\chi^{2}=14.00, p<0.001\right)$

Table IV shows the prevalence of active duodenitis and gastric metaplasia in the presence or absence of the various types of gastritis. Most cases were found in association with $H$ pylori positive gastritis, regardless of NSAID intake, although $H$ pylori was less common in patients receiving NSAID. Active duodenitis was uncommon in patients with normal gastric histology: its prevalence varied between $20 \%$ (on NSAIDs) and $24 \%$ (not on NSAIDs). It is also worth noting that 24 of 25 duodenal ulcers $(96 \%)$, found in all patients, were associated with active antral gastritis, and that gastric $H$ pylori was identified in 23 of duodenal ulcer patients $(92 \%)$. Logistic regression showed that gastric $H$ pylori and the combination of active duodenitis and gastric metaplasia were independent predictors of duodenal ulceration. On the other hand, only 11 (nine on NSAIDs) of 16 gastric ulcers $(69 \%)$ had $H$ pylori related gastritis; the remaining five gastric ulcers were found in association with chemical gastritis, which was found only in patients taking NSAIDs.

Table $\mathrm{V}$ shows the distribution of NSAIDs, with or without second line drugs in patients with active duodenitis and gastric metaplasia. The median duration of NSAID intake was three years, and second line drugs two years. Indomethacin, naproxen, and diclofenac were the most widely used NSAIDs. Patients taking diclofenac, ketoprofen or nabumetone were less likely to have active duodenitis and gastric metaplasia than other NSAIDs but the differences were not statistically significant. Also, the intake of second line drugs did not seem to influence the development of active duodentitis and gastric metaplasia, although such histological abnormalities, as well as gastric $H$ pylori, were less common in patients treated with gold injections.

\section{Discussion}

This study shows that active chronic duodenitis is less common in patients treated with NSAIDs, and that the prevalence of gastric metaplasia in the duodenum is not significantly reduced by chronic NSAID use. The study also shows a strong association between duodenal ulcers, active duodenitis, gastric metaplasia, and $H$ pylori related gastritis regardless of NSAID intake.

Active chronic duodenitis in patients not taking NSAIDs was more commonly diagnosed in our study than in that reported by some workers, ${ }^{3}$ who studied this abnormality in patients with non-ulcer dyspepsia. This can be explained by the absence of ulcers in their study, and by the nature of our scoring system. Such differences could not have influenced the interpretation of our findings with respect to the effect of NSAID on duodenal histology, because of two main reasons. Firstly, the same global score was applied to biopsy specimens taken from all our patients, regardless of NSAID intake, under blinded conditions. Secondly, and allowing for the possibility that our global score might have detected minor increases in the mucosal neutrophils in some cases of mild active duodenitis, the number of patients with heavy neutrophilic infiltration (severe active duodenitis) was also greater in the absence of NSAIDs.

Gastric metaplasia tended to occur less frequently in our patients receiving NSAIDs, but the differences did not reach statistical significance. This, together with its close association with active duodenitis, is in agreement with the findings of two other studies. ${ }^{10}$ High acidity of the duodenal contents has for a long time been found to be associated with gastric metaplasia, both in humans ${ }^{391112}$ and in laboratory animals. ${ }^{13}$ Acute exposure to NSAIDs is also known to stimulate gastric acid secretion, ${ }^{1+17}$ which, at least in theory, should increase the prevalence of

\begin{tabular}{|c|c|c|c|c|c|c|c|c|}
\hline & \multicolumn{4}{|c|}{ Receiving NSAID $(n=74)$} & \multicolumn{4}{|c|}{ Not receving $N S A I D(n=98)$} \\
\hline & No & $\begin{array}{l}\text { Gastric } \\
\text { H pylori }\end{array}$ & $\begin{array}{l}\text { Active } \\
\text { duodenitis }\end{array}$ & $\begin{array}{l}\text { Gastric } \\
\text { metaplasia }\end{array}$ & No & $\begin{array}{l}\text { Gastric } \\
\text { H pylori }\end{array}$ & $\begin{array}{l}\text { Active } \\
\text { duodenitis }\end{array}$ & $\begin{array}{l}\text { Gastric } \\
\text { metaplasia }\end{array}$ \\
\hline \multicolumn{9}{|l|}{ Chronic gastritis: } \\
\hline & 48 & 31 & 9 & 13 & 63 & 54 & 46 & 33 \\
\hline \multicolumn{2}{|l|}{ Special forms: } & - & 2 & 2 & 7 & 1 & 2 & 1 \\
\hline Reactive (chemical) & 10 & - & 4 & 1 & - & - & _- & _- \\
\hline Lymphocytic & 3 & 3 & 3 & 2 & 7 & 5 & 3 & $\overline{2}$ \\
\hline Normal & 10 & - & 2 & 2 & 21 & 2 & 5 & 3 \\
\hline
\end{tabular}


TABLE V Details of NSAIDs and second line drugs in patients with active chronic duodenitis and gastric metaplasia

\begin{tabular}{lrccl}
\hline & No & $\begin{array}{l}\text { Gastric } \\
\text { H pylori }\end{array}$ & $\begin{array}{l}\text { Active } \\
\text { duodenitis }\end{array}$ & $\begin{array}{l}\text { Gastric } \\
\text { metaplasia }\end{array}$ \\
\hline Indomethacin & 13 & 6 & 5 & 4 \\
Naproxen & 12 & 6 & 5 & 5 \\
Diclofenac & 7 & 2 & - & - \\
Ketoprofen & 6 & 3 & - & 1 \\
Nabumetone & 6 & 5 & 2 & 1 \\
Ibuprofen & 5 & 2 & 1 & 2 \\
Others & 24 & 10 & 5 & 6 \\
Sulphasalazine & 18 & 14 & 12 & 8 \\
Gold (im) & 13 & 5 & 5 & 2 \\
Penicillamine & 6 & 2 & 3 & 1 \\
\hline
\end{tabular}

* These included four patients or less for each of the following agents: azapropazone, fenbufen, flurbiprofen, piroxicam, etodalac, tiaprofenic acid, and sulindac.

gastric metaplasia. The second, however, has not been seen in our study or in others ${ }^{910}$ and could be related to the possibility that gastric acid secretion might not necessarily be raised when NSAIDs are taken on longterm basis, three years in this study.

Active chronic duodenitis was also less common in our patients taking NSAIDs. The reason for this is not clear but it could be explained by the finding of a lower prevalence of $H$ pylori in NSAID patients, ${ }^{818-20}$ and by the tendency of NSAID related damage to be maximal in the gastric antrum. ${ }^{2122}$ Although no specific histological picture could be shown in the duodenal mucosa of NSAID patients, the relative lack of heavy neutrophilic and plasma cell infiltration in the duodenum is reminiscent of some aspects of chemical gastritis. ${ }^{6823}$ In the absence of gastroduodenal surgery, the last is mostly found in chronic NSAID users, as shown in this study and others. ${ }^{6823}$

Patients with active duodenitis had comparable proportions of cases with gastric $H$ pylori, regardless of NSAID intake, and despite the differences in the overall prevalence of $H$ pylori in the presence or absence of NSAID. This emphasises the role of $H$ pylori in the pathogenesis of active duodenitis. ${ }^{10}$ It is worth noting that in the presence of gastric metaplasia $H$ pylori was almost as reliably isolated from the duodenum as from the gastric mucosa and this reflects the natural history of this infection, being dependent on the presence of gastric type epithelium.

Patients receiving NSAIDs had 11 duodenal ulcers 11/74 (15\%) compared with 14/98 (14\%) in those not receiving NSAIDs. Similar numbers of duodenal ulcers (25-30\%) were also seen in patients with active duodenitis or gastric metaplasia, or both, regardless of NSAID intake. Most patients with duodenal ulcers, however, in the presence or absence of NSAIDs, were found to have active duodenitis $(80 \%)$ and gastric metaplasia (64\%). The strong association between such histological and endoscopic entities is in agreement with the suggestion that duodenitis and duodenal ulceration might represent different points in a disease spectrum with a common underlying pathogenesis. ${ }^{1-3910}$ There was also a strong association between active duodenitis and $H$ pylori positive gastritis, which in turn highlights the potential benefits of eradicating $H$ pylori in minimising duodenal damage in NSAID patients. The same would apply to gastric ulcers, eight of which (8/14, $57 \%$ ) were positive for $H$ pylori. ${ }^{8}$

The relative rarity of active duodenitis in the NSAID group might explain, at least in part, why duodenal ulcers occur less commonly than gastric ulcers in such patients. ${ }^{2122}$ On the other hand, duodenal ulcers were still seen in comparable proportions in the presence or absence of NSAIDs, which could be because of other mechanisms of NSAID toxicity such as suppression of mucosal prostaglandins.

The prevalence of gastric $H$ pylori, active duodenitis, and gastric metaplasia was similar in patients taking the various NSAIDs with the exception of diclofenac and ketoprofen. The prevalence of such findings tended to be lower in patients treated with gold injections than in those receiving sulphasalazine and NSAIDs. ${ }^{24} \mathrm{~A}$ firm statement could not, however, be made because of the relatively small numbers of patients taking the individual NSAID with or without second line drugs in this study.

In conclusion, despite the relative lack of active duodenitis in NSAID patients, a strong association exists between duodenal ulcers, active duodenitis, gastric metaplasia, and $H$ pylori positive gastritis regardless of NSAID intake. This might be relevant to the understanding of the pathogenesis and the treatment of duodenal ulcers in chronic NSAID users. The potential benefits of eradicating $H$ pylori in such patients are, however, still speculative, and their value remains to be proved.

We wish to thank Miss Pamela Boothman for her help in $H$ pylor cultures, and Mrs Ruth Simpson for her secretarial assistance.

1 Dixon MF, Sobala GM. Gastritis and duodenitis: the histopathological spectrum. Eur f Gastroenterol Hepatol 1992; 4 (suppl 2): S17-23.

2 Sipponen $P$. Long-term consequences of gastroduodenal inflammation. Eurf Gastroenterol Hepatol 1992; 4 (suppl 2): inf5-9.

3 Wyatt JI, Rathbone BJ, Dixon MF, Heatley RV. Campylobacter pyloridis and acid induced gastric metaplasia in the bacter pyloridis and acid induced gastric metaplasia in the

4 Taha AS, Boothman P, Holland P, et al. Gastric mucosal prostaglandin synthesis in the presence of Campylobacter pylori in patients with gastric ulcers and non-ulcer dyspepsia. Am $\mathcal{F}$ Gastroenterol 1990; 85: 47-50.

5 Misiewicz JJ, Tytgat GNJ, Goodwin CS, et al. The Sydney System: a new classification of gastritis. Working Party Reports of the World Congress of Gastroenterology. Oxford: Blackwell Scientific Publications, 1990: 1-10.

6 Dixon MF, O'Connor HJ, Axon ATR, King RFJG, Johnston D. Reflux gastritis: distinct histopathological entity? $\mathcal{F}$ Clin Pathol 1986; 39: 524-30.

7 Dixon MF, Wyatt JI, Burke DA, Rathbone BJ. Lymphocytic gastritis - relationship to Campylobacter pylori infection. gastritis - relationship to Can

8 Taha AS, Nakshabendi I, Lee FD, Sturrock RD, Russell RI. Chemical and Helicobacter pylori related gastritis in patients receiving non-steroidal anti-inflammatory drugs - compari son and correlation with peptic ulceration. $\mathcal{F}$ Clin Patho 1992; 45: 135-9.

9 Carrick J, Lee A, Hazell S, Ralston M, Daskalopoulos G. Campylobacter pylori, duodenal ulcer, and gastric metaplasia: possible role of functional heterotopic tissue in ulcerogenesis. Gut 1989; 30: 790-7.

10 Wyatt JI, Rathbone BJ, Sobala GM, Shallcross T, Heatley RV, Axon ATR, et al. Gastric epithelium in the duodenum its association with Helicobacter pylori and inflammation. f Clin Pathol 1990; 43: 981-6.

11 James AH. Gastric epithelium in the duodenum. Gut 1964; 5 : 285-94.

12 Patrick WJA, Denham D, Forrest APM. Mucosa change in the human duodenum: a light and electron microscopic the human duodenum: a light and electron microscopic study and correlation

13 Rhodes J. Experimental production of gastric epithelium in the duodenum. Gut 1964; 5: 454-8.

14 Gerkens JR, Shand DG, Flexner C, Nies A, Oates J, Data J Effect of indomethacin and aspirin on gastric blood flow and acid secretion. F Pharmacol Exp Ther 1977; 203: 646-52

15 Feldman M, Colturic TJ. Effect of indomethacin on gastric acid and bicarbonate secretion in humans. Gastroenterology $1984 ; 87$ : 1339-43. 
16 Levine RA, Schwartzel EH. Effect of indomethacin on basa and histamine stimulated gastric acid secretion. Gut 1984 25: 718-22.

17 Levine RA, Jyotirmoy N, King RL. Non-salicylate nonsteroidal anti-inflammatory drugs augment pre-stimulated acid secretion in rabbit parietal cells. Investigations of the mechanisms of action. Gastroenterology 1991; 101: 756-65.

18 Marshall BJ, McGechie DB, Rogers PA, Glancy RJ. Pyloric Campylobacter infections and gastroduodenal disease. Med 7 Aust 1985; 142: 439-44.

19 Casselli M, Pazzi P, La Corte R, Alcotti A, Trevisani L Stabellini G. Campylobacter like organisms, non-steroidal anti-inflammatory drugs, and gastric lesions in patients with rheumatoid arthritis. Digestion 1989; 44: 101-4.

20 Laine L, Marin-Sorensen M, Weinstein WM. Helicobacter pylori (HP) prevalence and mucosal injury in gastric ulcers GUs): relationship to chronic non-steroidal anti-inflammatory drug (NSAID) ingestion. Gastroenterology 1991; 100 Al03.

21 Farah D, Sturrock RD, Russell RI. Peptic ulceration in rheumatoid arthritis. Ann Rheum Dis 1988; 47: 478-80.

22 Taha AS, Capell HA, Sturrock RD, Russell RI. Non-steroidal peptic damage in rheumatoid patients receiving second-line drugs. Am $\mathcal{F}$ Gastroenterol 1991; 86: 1588-91.

23 Sobala GM, Fing RFG, Axon ATR, Dixon MF. Reflux gastritis in the intact stomach. F Clin Pathol 1990; 43: 303-6. 24 Taha AS, Sturrock RD, Russell RI. Helicobacter pylori and peptic ulcers in rheumatoid patients receiving gold, sulphasalazine, and non-steroidal anti-inflammatory drugs. Am $\mathcal{Y}$
Gastroenterol 1992; 87: 1732-5. 